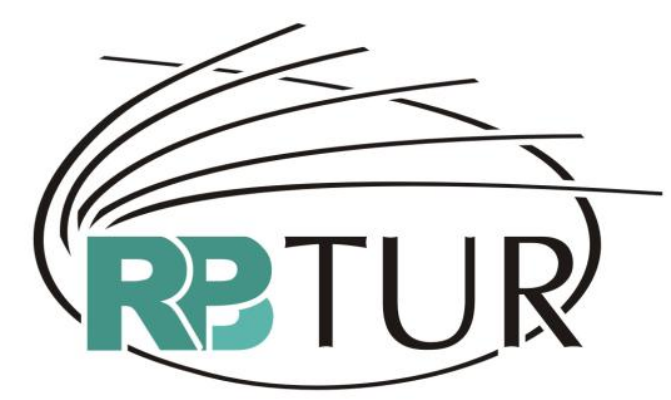

REVISTA BRASILEIRA DE PESQUISA EM TURISMO

\title{
ENSINO SUPERIOR EM TURISMO NO BRASIL: A PRODUÇÃO ACADÊMICA DE DISSERTAÇÕES E TESES (2000-2009)
}

\author{
TOURISM HIGHER EDUCATION IN BRAZIL: AN OVERVIEW OF \\ MASTER AND DOCTORAL THESES (2000-2009)
}

\section{LA ENSEÑANZA SUPERIOR DE TURISMO EN BRASIL: LA PRODUCCIÓN ACADÉMICA DE TESIS DE MAESTRÍA Y DOCTORALES (2000-2009)}

\author{
Juliana Ribeiro de Lima ${ }^{1}$ \\ Mirian Rejowski ${ }^{2}$
}

\begin{abstract}
Resumo: Pesquisa exploratório-descritiva, de caráter documental, acerca das dissertações de mestrado e teses de doutorado sobre ensino superior em Turismo no Brasil. Foi realizada uma consulta a bancos de dissertações e teses, e de sites de instituições de ensino superior, reunindo uma amostra de 45 pesquisas, produzidas de 2000 a 2009, cujos títulos, resumos e palavras-chave foram registrados em formulário do Microsoft Access. Apresenta o mapeamento e a análise das dissertações e teses, a partir da sua caracterização geral, temática e abrangência espacial. A maioria das pesquisas é de dissertações de mestrado, de autoria de pesquisadoras com graduação em Turismo e que atuam como docentes em instituições de ensino superior. Em relação aos temas abordados, os cursos de graduação (bacharelados) em Turismo foram os mais estudados com uma interessante cobertura temática, embora quase sempre pontual, com maior concentração sobre a formação profissional. As poucas pesquisas sobre os cursos de pós-graduação oferecem análises aprofundadas fundamentadas em referencial teórico-metodológico da Educação e da Ciência da Informação. A falta de padronização e fragilidade das palavras-chave indica a premência da utilização de vocabulários controlados em Turismo.
\end{abstract}

${ }^{1}$ Bacharel em Turismo pela Universidade de Sorocaba (UNISO), Especialista em Docência para o Ensino Superior pelo SENAC/SP e Mestre em Hospitalidade pela Universidade Anhembi Morumbi (UAM). Email: julisrlima@yahoo.com.br

2 Bacharel em Turismo, Doutora em Ciências da Comunicação e Livre Docente em Teoria do Turismo e do Lazer pela Universidade de São Paulo (USP). Docente do Mestrado em Hospitalidade da Universidade Anhembi Morumbi (UAM). Pesquisadora do CNPq e líder do grupo de pesquisa Inovação e Qualificação em Turismo e Hospitalidade. Email: mirwski@gmail.com 
ISSN: $1982-6125$

Palavras chave: Turismo. Ensino superior. Produção científica. Dissertações e teses. Brasil.

Abstract: This is an exploratory-descriptive research aiming to analyze Master and PHD Theses presented in Brazil. The research was held at data bases and websites of Higher Education institutions. A sample of 45 theses presented from 2000 to 2009, whose titles, abstracts and keywords were recorded in Access form was analyzed on general, thematic and geographical basis. Most are Master Theses authored by Bachelors in Tourism teaching in Higher Education institutions. As for subjects, the result is that most researches are about undergraduate tourism programs, with emphasis in vocational training. The few researches found about Pos Graduate programs present in-depth analysis based on theoretical and methodological framework borrowed from Education and Information Science. Lack of standardization and fragility of keywords indicates the urgency of use of controlled glossaries in Tourism.

Keywords: Tourism Higher education. Scientific research. Master theses. PHD theses. Brazil.

Resumen: Investigación exploratorio-descriptiva, de carácter documental, sobre las tesis de maestría y doctorado con el tema enseñanza superior en Turismo en Brasil. Se realizó una consulta en bancos de dados y sitios de instituciones de enseñanza superior, obteniéndose una muestra de 45 investigaciones llevadas a cabo entre 2000 y 2009, cuyos títulos, resúmenes y palabras-clave se registraron en formulario del programa Access, Presenta el mapeamiento y el análisis de las tesis de maestría y doctorado, a partir de una caracterización general, temática y espacial. Se trata en su mayor parte de tesis de maestría, de autoría de investigadores con graduación en turismo que trabajan como docentes en instituciones de enseñanza superior. En lo que respecta a los temas, lo más estudiado fueron los cursos de graduación con mayor concentración en la formación profesional. Las pocas investigaciones sobre los cursos de posgrado hacen análisis en profundidad con referencial metodológico de la Educación y la Ciencia de la Información. La falta de estandarización y la fragilidad de las palabras clave indican la necesidad urgente de utilización de vocabularios controlados.

Palabras clave: Turismo. Educación superior. Investigación científica. Tesis de maestría y doctorado. Brasil.

\section{Introdução}

Este artigo apresenta uma releitura da fundamentação teórica e dos principais resultados da dissertação de mestrado de Lima (2011), cujo objetivo geral foi o de observar a configuração do conhecimento sobre ensino superior em Turismo no Brasil oriundo de pesquisas acadêmicas. Com esse propósito, fez-se o mapeamento da produção científica sobre o tema, com foco em dissertações e teses brasileiras, a fim de: a) levantar e caracterizar as pesquisas, demonstrando a sua evolução até o final da década de 2000; b) 
classificar e analisar o conteúdo dessas pesquisas, de forma a compreender a abrangência do conhecimento nelas produzido; c) discutir essa produção científica em relação aos temas e subtemas enfocados sobre o ensino de graduação e pós-graduação. Configura-se como uma pesquisa exploratóriodescritiva, de caráter documental, cujo modelo metodológico baseou-se em estudos sobre a produção científica em Turismo de Kim (1998), Bastos e Fedrizzi (2007), e Rejowski (2010).

Na primeira etapa procedeu-se a busca das dissertações de mestrado e teses de doutorado em banco de teses da Coordenadoria de Aperfeiçoamento de Pessoal de Nível Superior (CAPES) e sites de instituições de ensino superior com programas ou linhas de pesquisa na área. Selecionaram-se as pesquisas produzidas em programas de pós-graduação stricto sensu recomendados pela Capes, com foco em cursos de graduação em nível de bacharelado ou em cursos de pós-graduação em Turismo e Hospitalidade em nível de lato ou sctricto sensu ${ }^{3}$. Os dados coletados foram registrados em planilha do software Acess nos seguintes campos: autor, título, resumo, tipo (mestrado ou doutorado), ano, orientador, programa, instituição, descritores e locais de estudo.

Na segunda etapa acessou-se o currículo dos autores das dissertações e teses selecionadas na plataforma Lattes do Conselho Nacional de Desenvolvimento Científico e Tecnológico (CNPq). Os dados foram registrados em planilha do software Excel nos seguintes campos: nome, sexo, formação acadêmica (graduação) e atuação profissional.

Como esta pesquisa trata particularmente das temáticas sobre o Ensino Superior em Turismo, importa considerar os tesauros ou vocabulários controlados da área. Para Momm e Santos (2010, p. 376), o tesauro "pode auxiliar, não só na recuperação da informação, mas também na representação

3 Isto porque as dissertações e teses levantadas no período sobre cursos seqüenciais e tecnológicos em Turismo tinham pouca representatividade - 0 e 1 , respectivamente. Por essa mesma razão também não foram consideradas as pesquisas sobre os cursos superiores de Hotelaria, sendo 4 referentes a cursos de bacharelado e 1 a curso tecnológico. 
do conhecimento científico produzido", identificando, assim, o estado da arte de uma determinada área de estudo.

No tesauro da OMT (2001), aparecem 19 termos maiores, sendo que o termo Formação e emprego apresenta os seguintes termos menores: Emprego, Ensino turístico, Formação profissional, Profissões turísticas, Profissões de hotelaria e restaurantes, e Qualificação. No tesauro do Centro de Documentação Turística da Espanha há um menor número de termos maiores (9), sendo que o termo Educação e formação em Turismo indica 6 subtemas: Formação turística, Instituições educacionais, Cursos de pós-graduação, Bolsa de estudo, Currículo educacional e Titulações (ESPAÑA, 2003).

Este artigo inicia-se com considerações sobre o contexto evolutivo do ensino superior no Brasil a partir da época da criação dos primeiros cursos de graduação em Turismo, e sobre a pesquisa e produção científica baseada em estudos referenciais. Em seguida apresenta o mapeamento das dissertações e teses sobre ensino superior em Turismo no Brasil, sendo que alguns trechos dos resumos das pesquisas foram transcritos em italic a fim de esclarecer as abordagens temáticas das mesmas.

\section{Apontamentos sobre o ensino superior e a pesquisa em Turismo no Brasil}

Na década de 1970 tem-se o início da oferta de cursos de graduação em Turismo no Brasil, a maioria dos quais em instituições privadas, mediante o estímulo do governo à criação de cursos de caráter profissionalizante (SOUZA, 2001; DENCKER, 2006). Nessa época vigoraram dois modelos de formação: um da Faculdade Morumbi de caráter profissionalizante e dirigido ao mercado, e outro da Universidade de São Paulo de caráter mais acadêmico e voltado à formação multidisciplinar e humanística ${ }^{4}$. No entanto, ambos se sustentavam

4 O curso de Turismo da Faculdade do Morumbi, hoje Universidade Anhembi Morumbi, foi criado em 1971 e o curso da Universidade de São Paulo no segundo semestre de 1973, como opção do bacharelado em Comunicação Social e logo em seguida desvinculado deste. 
no eixo central do planejamento turístico, então "cultuado" pelos setores públicos, e eram ofertados em nível de bacharelado (REJOWSKI, 2010).

De um crescimento tímido e estagnação nas décadas de 1970 e 1980, passa-se para um crescimento progressivo na década de 1990, e uma grande expansão até meados da década seguinte, quando tem início um processo de estagnação e declínio principalmente em cursos de instituições privadas (ANSARAH, 2002; RUSCHMANN, 2002; REJOWSKI, 2010).

Matias (2002, p. 9) cita que na segunda metade dos anos de 1990, a maioria dos cursos abertos "não dispunha de professores formados e/ou especializados [...], comprometendo assim, a formação superior". Para Ruschmann (2002) a grande expansão dos cursos de turismo foi provocada pelo Programa de Municipalização do Turismo (PNMT) ${ }^{5}$ do governo federal que estimulava o desenvolvimento do turismo a partir do município, e daí a necessidade de recursos humanos na área.

Assinala-se que em toda essa trajetória proliferaram poucos cursos em instituições públicas, ao lado de muitos cursos em instituições privadas. Para estas últimas, havia um nicho de mercado a ser explorado, o qual deixou de ser atrativo com a abertura de novos cursos (Hotelaria, Gastronomia, Eventos etc.) em diferentes modalidades de ensino superior (bacharelado, de tecnologia, seqüencial). Apenas na segunda metade de 2000 é que ocorre alguma expansão dos cursos em universidades públicas, principalmente nos estados de São Paulo e Rio de Janeiro. No entanto, nessa mesma época iniciase a redução do número de alunos e o encerramento de cursos em instituições privadas, refletindo, segundo Carvalho (2008), ou problemas de sobrevivência dos cursos ou apenas "acomodações" do mercado.

Com relação à formação em nível de pós-graduação lato sensu (especialização), não se pode traçar um panorama evolutivo, por falta de dados oficiais e estudos particulares. Em relação à pós-graduação "stricto

${ }^{5}$ Esse programa foi implantado e desenvolvido no Brasil entre 1994 e 2001; "previa uma abordagem comunitária participativa e a formação de Conselhos e Planos de Turismo com uma proposta teoricamente ascendente, cujos fundamentos derivariam das bases da sociedade" (BRUSADIN, 2005, p. 88). 
ISSN: $1982-6125$

sensu" em Turismo e áreas afins, afirma-se que a linha de pesquisa Turismo e Lazer do programa de mestrado e doutorado em Ciências da Comunicação da USP teve papel fundamental, principalmente na década de 1990 à primeira metade da década de 2000, titulando muitos graduados que passaram a atuar como docentes em todo o Brasil. Os programas específicos em Turismo surgiram somente a partir da década de 1990, com o Mestrado em Turismo e Lazer da USP (1993 a 1998), e o Mestrado em Turismo e Hotelaria da Universidade do Vale do Itajaí (UNIVALI) iniciado em 1997.

A partir de 2000 outras universidades privadas criaram novos mestrados, sendo que em 2011 tem-se a oferta de seis programas recomendados pela Capes com as suas respectivas datas de início: Mestrado em Turismo e Hotelaria (1997) na Universidade do Vale do Itajaí (UNIVALI), em Balneário Camburiú (SC); Mestrado em Turismo (2001) na Universidade Caxias do Sul (UCS), em Caxias do Sul (RS); Mestrado em Hospitalidade (2002) na Universidade Anhembi Morumbi, em São Paulo (SP); Mestrado em Turismo (2007) na Universidade de Brasília, em Brasília (DF); Mestrado em Lazer (2007) na Universidade Federal de Minas Gerais (UFMG), em Belo Horizonte; Mestrado em Turismo (2008) na Universidade Federal do Rio Grande do Norte (UFRN), em Natal (RN).

Todos esses mestrados são acadêmicos, exceto o da UnB que é profissionalizante. Em 2011 também foi autorizado o Mestrado Profissionalizante em Gestão de Negócios Turísticos na Universidade Estadual do Ceará (Fortaleza, CE), o qual deverá iniciar em breve o seu funcionamento. Em 2009 a UNIVALI passou a oferecer um doutorado em Administração e Turismo, e em 2010 um mestrado interinstitucional com o Centro Universitário do Norte (UNINORTE) em Manaus. Há dois mestrados que foram descredenciados pela Capes em 2011, o Mestrado em Cultura e Turismo da Universidade Estadual de Santa Cruz, em Ilhéus (BA), e o Mestrado em Turismo e Meio Ambiente do Centro Universitário UNA, em Belo Horizonte (MG), cujas turmas estão sendo finalizadas. 
Nesses programas são desenvolvidas pesquisas científicas denominadas dissertações de mestrado e teses de doutorado, como exigência parcial para a obtenção dos títulos de mestre e de doutor, respectivamente. No entanto, a produção de pesquisas sobre Turismo não se restringe aos programas específicos da área; estas também são desenvolvidas em programas das mais diversas áreas, principalmente no âmbito das Ciências Humanas e Sociais, mas não restritas a estas (SCHLÜTER, 2000).

No tocante aos estudos sobre a produção científica em Turismo, estes tiveram início na década de 1980 com o estudo pioneiro de Jafari e Aaser (1988) sobre um conjunto de 157 teses de doutorado sobre Turismo produzidas nos Estados Unidos entre 1951 e 1987 com base no Dissertation Abstract Index (DAI). Esses autores observaram que as áreas mais antigas e tradicionais a produzir teses eram a Geografia, a Economia e a Antropologia, sendo a primeira delas a mais antiga.

Esse estudo incentivou outros estudos em vários países, com o intuito de mapear a evolução das pesquisas científicas e a compreensão do estado da arte do conhecimento científico em Turismo, como os de Hall (1991) na Austrália e Boterill (2002) no Reino Unido. No Brasil pesquisas com esse foco tiveram início na década de 1990 com a tese de doutorado de Rejowski (1993), que tratou da configuração e sistematização documental de 55 dissertações e teses no período de 1975 a 1992. Quatro anos mais tarde essa autora analisou 102 pesquisas acadêmicas até 1995 e no final da década de 2000 centralizou suas pesquisas nas teses de doutorado (REJOWSKI, 1997; 2010), e constatou que as principais áreas produtoras foram a Comunicação e a Geografia, sendo esta última a mais antiga.

Outros estudiosos seguiram tal temática adaptando o modelo dessa autora à análise de dissertações e teses, como Bastos e Fedrizzi (2007) e Bastos (2008) sobre a produção do Mestrado em Hospitalidade da Universidade Anhembi Morumbi; Gomes (2004) sobre a produção brasileira com o tema Lazer; Pinto e Babinski (2006) sobre a produção do Mestrado em Turismo da Universidade de Caxias do Sul; e Santos, Possamai e Marinho 
(2009) sobre as teses de doutorado produzidas no Brasil de 2005 a 2007 . Dentre essas pesquisas, destaca-se a última que objetivou enquadrar a produção das teses nas plataformas de Jafar Jafari (1994), e identificar vínculos com as seguintes abordagens de estudo: sistêmica (BENI, 1988; 2001), fenomenológica (PANOSSO NETTO, 2005) e para além do fenômeno (MÖESCH, 2002). Como resultados, as autoras apontaram que

[...] o turismo é predominantemente analisado à luz de outras áreas de conhecimento e apontam [...] que a pesquisa, no referido período, se situa na Plataforma de Conhecimento mantendo elos com as da Defesa, da Advertência e da Adaptação. Por outro lado, de modo incipiente, começa a instaurar-se um novo cenário da pesquisa em turismo, mediante o intuito de ultrapassar o âmbito factual das atividades turísticas e redimensionar a compreensão do turismo como fenômeno. Questiona-se assim se o estudo do turismo estaria desenvolvendo uma nova dimensão dentro da Plataforma de Conhecimento ou estaria sendo desenvolvida uma nova plataforma, a Plataforma da Epistemologia do Turismo. (SANTOS; POSSAMAI; MARINHO; 2009, p. 1)

Relembra-se que Jafar Jafari apresenta uma evolução dos estudos turísticos em quatro plataformas: a) plataforma de defesa (década de 1960), na qual as pesquisas abordam os aspectos positivos do turismo; b) plataforma de advertência (década de 1970), cujos estudos se debruçam sobre os aspectos negativos do turismo; c) plataforma de adaptação (década de 1980), com trabalhos que buscam o equilíbrio entre os efeitos positivos e negativos do turismo (formas alternativas de turismo); d) plataforma de conhecimento científico (década de 1990), cujas pesquisas buscam explicações mais amplas e teorias do conhecimento em turismo (JAFARI, 1994). Todas essas plataformas continuam a existir na atualidade e o autor mais recentemente criou uma nova plataforma, a do turismo como um bem público (JAFARI, 2005).

Para rever a abordagem sistêmica, retoma-se uma relevante pesquisa sobre os principais teóricos do Turismo desenvolvida por Panosso Netto 
(2005), que os distribuiu nas seguintes fases: pré-paradigmática - na qual se pode destacar Jafar Jafari e Brent Ritchie, paradigmática -, Mário Carlos Beni, e novas abordagens - John Tribe. O autor não cita Möesch (2004), cuja pesquisa pode se inserir na fase de transição ou de novas abordagens. Faz-se a seguir uma breve apreciação das propostas teóricas desses pesquisadores.

Jafari e Ritchie (1981) apresentaram a estrutura da educação superior em Turismo em um modelo interdisciplinar dos estudos turísticos, composto por 16 disciplinas: sociologia, economia, psicologia, antropologia, ciência política, geografia, ecologia, agricultura, parque e recreação, planejamento urbano e regional, marketing, direito, administração, transporte, administração de hotéis e restaurantes, e educação. Esse modelo, embora revisto por Jafari (2005) não é plenamente aceito, pois não se sustentou ao ser aplicado e ainda não prevê adaptação a diferentes contextos e realidades; outro questionamento é em relação ao próprio conjunto de disciplinas que o compõem.

Beni (1988; 2001) desenvolveu um modelo baseado na teoria de sistemas, denominado SISTUR - Sistema de Turismo, composto pelos seguintes conjuntos e respectivos subsistemas: a) conjunto (ou sistema) das relações ambientais: subsistemas econômico, cultural, ecológico e social; b) conjunto da organização estrutural: subsistemas da infra-estrutura e da superestrutura; c) conjunto das ações operacionais: subsistemas da produção (oferta), consumo (demanda) e distribuição. Trata-se de um modelo fundamentado na idéia de mercado turístico, que fundamentou grande parte das pesquisas e propostas curriculares de bacharelados na década de 1990, reafirmando-se como paradigma dominante no Brasil. No entanto, concorda-se com Panosso Netto (2005) que a abordagem sistêmica tem mostrado claros sinais de seu esgotamento, havendo necessidade de um novo paradigma para os estudos turísticos.

Um estudo não sistêmico é o de Tribe (1997) que elaborou o modelo de produção do conhecimento sobre turismo a partir de dois campos: a) campo dos negócios turísticos, produzido pelo "trade turístico"; b) campo dos 
negócios "não turísticos", produzido na universidade. Ao redor desses campos circulam as disciplinas e subdisciplinas e entre eles há uma zona de purificação de teorias onde o conhecimento turístico é produzido. Considera dessa forma que o turismo é uma "indisciplina" e nunca virá a se constituir como tal, o que nem sempre é aceito pela comunidade científica.

Por outro lado, a busca de novas teorizações tem levado a releituras do paradigma sistêmico face à problemática ambiental do planeta e a viabilidade da vida humana futura, considerando ainda a complexidade. Um desses estudos é o de Möesch (2004) com a proposta de um sistema turístico orgânico holográfico, aberto e eco-orgânico, onde o sujeito turístico é o componente central ao redor do qual gravitam os seguintes componentes: ideologia, comunicação, nomadismo/deslocamento, tempo, tecnologia, imaginário, espaço, sedentarismo/encontro, diversão e economia.

Por fim, um modelo mais recente que vem sendo desenvolvido desde 2007 em virtude de um movimento internacional denominado TEFI - Tourism Education Future Iniciatives. Nele a ética, sustentabilidade e internacionalização/globalização constituem as forças de pressão para a "mudança dos paradigmas educacionais vigentes na formação superior em turismo" (SOGAYAR; REJOWSKI, 2011, p. 282). Essas forças de pressão impõem cinco "novos" valores da educação superior em Turismo: ética, profissionalismo, zelo, conhecimento e mutualidade. Uma nova força de pressão ou um novo valor a ser incorporado nesse modelo é a hospitalidade, de um lado pela "inclusão social, cidadania e humanização, e de outro pela cadeia produtiva mais humanizada e inclusiva do setor turístico" (SOGAYAR; REJOWSKI, 2011, p. 295).

\section{Ensino superior em Turismo nas pesquisas acadêmicas}

\section{Caracterização geral}

Foram identificadas 45 pesquisas acadêmicas sobre ensino superior em Turismo no Brasil, com destaque para as dissertações de mestrado com 40 
ISSN: $1982-6125$

pesquisas (89\%). As poucas teses de doutorado identificadas (5, 11\%) demonstram o pouco interesse de doutores pelo asssunto. As pesquisas distribuem-se no período de 2000 a 2009 (figura 1), o que indica um tema recente na produção científica em Turismo, considerando quarenta anos de formação superior na área.

Verifica-se que a produção é intermitente de 2000 a 2003, ascendente de 2003 a 2006 e descendente entre 2007 e 2008, com um novo crescimento em 2009; o ápice da produção situa-se em 2006 com 9 pesquisas (figura 1). Lembra-se que a primeira metade da década de 2000 registrou um "boom" dos cursos de graduação em Turismo (RUSCHMANN, 2002; REJOWSKI, 2010), 0 que pode ter motivado o interesse em pesquisar o tema e a busca de títulos acadêmicos pelos docentes desses cursos ou por recém formados que vislumbraram a docência com um novo campo de atuação profissional.

Em relação às instituições produtoras, as pesquisas se concentram em instituições situadas nas regiões Sudeste e Sul (93\%), com destaque para a cidade de São Paulo. Entre as instituições destacam-se as seguintes: Universidade de São Paulo (6), Pontifícia Universidade Católica de São Paulo (4), Universidade Federal de Santa Catarina (4) e Universidade do Vale do Itajaí (4). Outras instituições produziram entre 1 e 2 pesquisas.

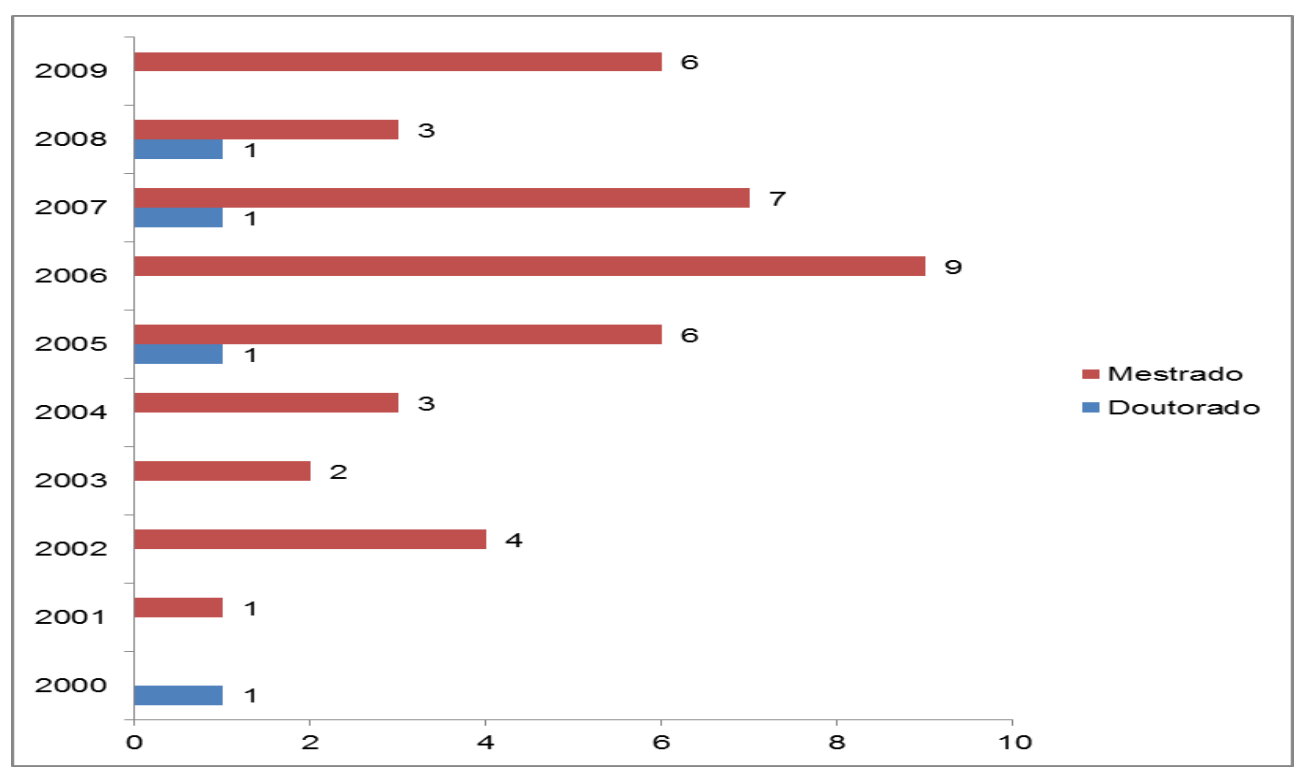


Figura 1 - Pesquisas acadêmicas sobre ensino superior em Turismo por ano de produção - Brasil - 2000 a 2009

Fonte: Elaboração própria (2011).

Em relação às principais áreas produtoras, tem-se a Educação e o Turismo, com 14 e 13 pesquisas respectivamente, seguidas da Administração com 6 pesquisas. Outras áreas produtoras foram: Geografia (3), Ciências da Comunicação (3), Ciência da Informação (2), Engenharia (2), Psicologia (1) e Ciências da Saúde e do Ambiente (1).

As pesquisas foram orientadas por 39 diferentes orientadores, a maioria dos quais orientou apenas uma pesquisa $(36,80 \%)$. Dos orientadores que orientaram 2 ou mais trabalhos, tem-se Mirian Rejowski (5, 11\%), Mário Carlos Beni $(2,4 \%)$ e Marcos Tarciso Massetto (2, 4\%). Esse resultado mostra pouca concentração de docentes orientadores no tema, não configurando uma linha de pesquisa consolidada.

Quanto aos pesquisadores-autores das pesquisas, 71\% (31) são do sexo feminino e têm alguma formação em Turismo e áreas afins, principalmente como bacharéis em Turismo. Mais da metade atua como docente (20,44\%), sendo que as outras ocupações registradas foram as de docente e consultor (4), docente e profissional (2), consultor (1) e profissional (1). Esclarece-se que os demais autores ou não tinham o currículo Lattes ou não registraram a sua atuação profissional nos mesmos (19, 35\%).

\section{Análise temática}

O Ensino Superior em Turismo foi analisado a partir de um conjunto de quatro descritores. O primeiro deles indica o tipo de curso estudado, ou seja, Graduação em Turismo, Graduação em Turismo e Hotelaria, Graduação em Turismo e Lazer, e Pós-graduação em Turismo e Hospitalidade; os demais indicam subtemas ou assuntos investigados. 


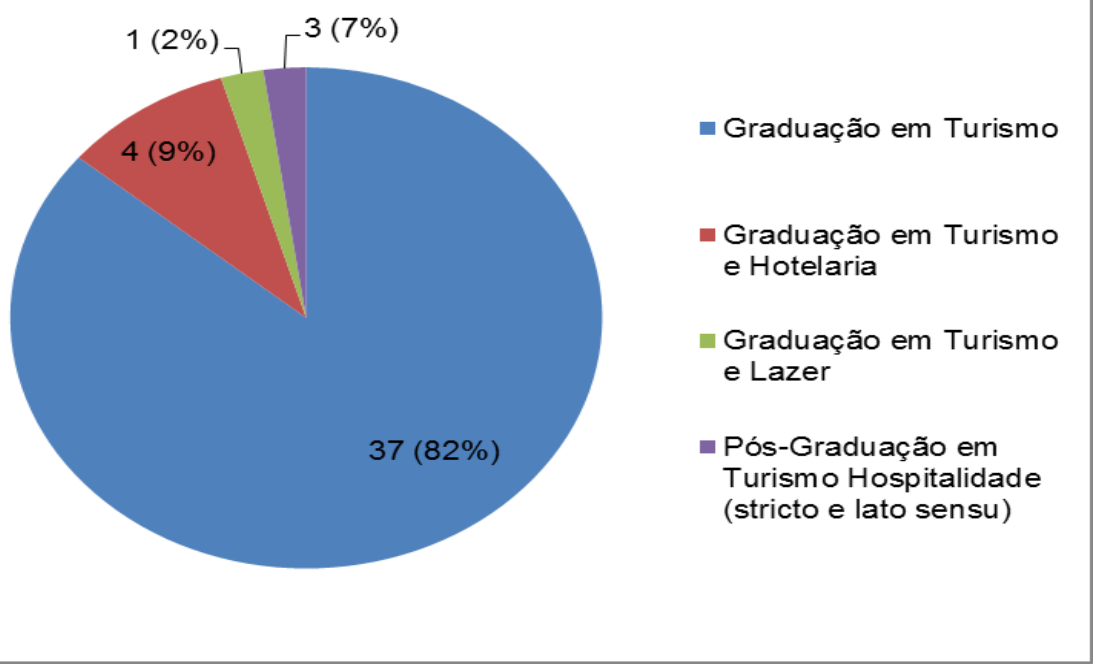

Figura 2 - Tema (descritor 1) das dissertações e teses sobre ensino superior em Turismo - Brasil - 2000 a 2009

Fonte: Elaboração própria (2011).

Conforme a figura 2 verifica-se que a maioria das pesquisas (37, 82\%) aborda a graduação em Turismo, seguidas pelas pesquisas sobre a Graduação em Turismo e Hotelaria (4, 9\%), Pós-graduação em Turismo e Hospitalidade (3, 7\%) e Graduação em Turismo e Lazer (1, 2\%). Essa preferência em estudar a formação superior em Turismo parece estar associada também ao período de ascensão e explosão da oferta de cursos no Brasil (ANSARAH, 2002; CARVALHO, 2008).

Distribuindo os subtemas (descritores 2 a 4) pelo tema (descritor 1) das pesquisas, tem-se 0 quadro 1 . Nota-se grande variedade de termos indicativos dos subtemas, com 7 grupos de descritores completos (do descritor 2 ao 4). Percebe-se também que os subtemas diminuem ao se detalhar o tema: o descritor 2 apresenta 33 termos; o descritor 3, 25 termos; e o descritor 4, 7 termos.

Cita-se ainda que alguns descritores foram descartados pela sua não representatividade e outros não existentes ficaram sem identificação, mesmo após várias releituras dos títulos, resumos e palavras-chave. Transparece, de um lado, a falta de consistência e ordenação das palavras-chave que devem 
representar com precisão o conteúdo das pesquisas; e, de outro, o desconhecimento de qualquer vocabulário controlado da área, inclusive do tesauro da OMT (2001).

Entre os temas e subtemas identificados nas pesquisas, três estão presentes nos tesauros consultados: Cursos de pós-graduação (ESPAÑA, 2003), Formação profissional (OMT, 2001; ESPAÑA, 2003) e Instituições educacionais (ESPAÑA, 2003). Essa situação reforça o pensamento de Momm e Santos (2010) sobre a fragilidade das palavras-chave das dissertações e teses em Turismo, e impõe a urgência de uma classificação temática da área.

Com relação às pesquisas sobre a Graduação em Turismo e Lazer (quadro 1), registra-se apenas um estudo que aborda essa formação, com foco na teoria e prática do estágio, apesar desse componente curricular ser obrigatório. A autora constatou a função do estágio mais como treinamento do que como um importante componente da formação do profissional, conforme indica o seguinte trecho do resumo da pesquisa:

[...] prevalece, no curso de Turismo e Lazer da FURB, tanto da parte da Universidade, do setor empresarial quanto dos estudantes, a visão do estágio como treinamento, não como instrumento de formação. Em função desta concepção há vários impedimentos para que ele cumpra seu objetivo de "complementação prática" da formação, desde a forma como é concebido até como é executado, acompanhado e avaliado. (DALLAGNOLLO, 2009, s.p.)

As pesquisas sobre a Graduação em Turismo e Hotelaria (quadro 1) apresentam 4 grupos de subtemas: a) atuação docente, com foco no desempenho profissional; b) ensino de administração; c) formação profissional; d) cursos superiores, com foco na qualidade. Alguns resumos não citavam claramente os resultados e as conclusões das pesquisas o que comprometeu a sua análise. Destacam-se os estudos acerca da visão do mercado sobre a formação desse bacharel, citando, por exemplo, que as competências requeridas pelo mercado ainda não correspondem àquelas desenvolvidas pelas IES, revelando uma discrepância de resultados na 
formação profissional (NEVES JÚNIOR, 2007, s.p.); ou da atuação de docentes inseridos em um

[...] difícil contexto de atuação do professor universitário de turismo/hotelaria que "deve ter um pé no mercado e outro na academia" a avaliar as dificuldades e ineficácia de um desenvolvimento docente isolado e/ou particular. [...]

[onde há] necessidade de adequação de um processo de desenvolvimento profissional de professores em conjunto com as instituições de ensino para a otimização docente.(GAETA, 2001, s.p.)

\begin{tabular}{|c|c|c|c|c|c|c|}
\hline \multirow{2}{*}{$\begin{array}{c}\text { Tema } \\
\text { (Descritor 1) }\end{array}$} & \multicolumn{2}{|l|}{$\begin{array}{c}\text { Subtema } \\
\text { (Descritor 2) }\end{array}$} & \multicolumn{2}{|l|}{$\begin{array}{c}\text { Subtema } \\
\text { (Descritor } 3 \text { ) }\end{array}$} & \multicolumn{2}{|c|}{$\begin{array}{c}\text { Subtema } \\
\text { (Descritor 4) }\end{array}$} \\
\hline & Nome & No & Nome & No & Nome & No \\
\hline \multirow[t]{3}{*}{$\begin{array}{l}\text { Pós-Graduação } \\
\text { em Turismo e } \\
\text { Hospitalidade }\end{array}$} & $\begin{array}{ll}\text { Bibliometria } & \text { e } \\
\text { cienciometria } & \end{array}$ & 1 & $\begin{array}{l}\text { Institucionalização } \\
\text { científica }\end{array}$ & 1 & $\begin{array}{l}\text { Pós- } \\
\text { graduação } \\
\text { stricto sensu }\end{array}$ & 1 \\
\hline & Formação docente & 1 & $\begin{array}{l}\text { Pós-graduação } \\
\text { lato-sensu }\end{array}$ & 1 & & \\
\hline & $\begin{array}{l}\text { Produção } \\
\text { acadêmica }\end{array}$ & 1 & $\begin{array}{ll}\text { Produção } & \text { do } \\
\text { conhecimento } & \end{array}$ & 1 & $\begin{array}{l}\text { Pós- } \\
\text { graduação } \\
\text { stricto-sensu }\end{array}$ & 1 \\
\hline $\begin{array}{l}\text { Graduação em } \\
\text { Turismo e Lazer }\end{array}$ & Formação & 1 & Estágio & 1 & $\begin{array}{l}\text { Teoria } \quad \mathrm{e} \\
\text { prática }\end{array}$ & 1 \\
\hline \multirow{4}{*}{$\begin{array}{lr}\text { Graduação } & \text { em } \\
\text { Turismo } & \text { e } \\
\text { Hotelaria } & \end{array}$} & Atuação docente & 1 & Desempenho & 1 & & \\
\hline & $\begin{array}{ll}\text { Ensino } & \text { de } \\
\text { administração } & \end{array}$ & 1 & & & & \\
\hline & $\begin{array}{l}\text { Formação } \\
\text { profissional }\end{array}$ & 1 & & & & \\
\hline & Cursos superiores & 1 & & & & \\
\hline \multirow[t]{8}{*}{$\begin{array}{l}\text { Graduação em } \\
\text { Turismo }\end{array}$} & Mentoria & 1 & $\begin{array}{l}\text { Professores } \\
\text { universitários }\end{array}$ & 1 & $\begin{array}{l}\text { Papel } \\
\text { atuação }\end{array}$ & 1 \\
\hline & $\begin{array}{ll}\text { Ensino } & \text { de } \\
\text { administração } & \\
\end{array}$ & 2 & & & & \\
\hline & $\begin{array}{ll}\begin{array}{l}\text { Produção } \\
\text { conhecimento }\end{array} & \text { do } \\
\end{array}$ & 1 & & & & \\
\hline & $\begin{array}{l}\text { Educação } \\
\text { ambiental }\end{array}$ & 1 & $\begin{array}{l}\text { Bacharel } \\
\text { turismo }\end{array}$ & & & \\
\hline & Políticas públicas & 1 & $\begin{array}{l}\text { Formação } \\
\text { profissional }\end{array}$ & 1 & & \\
\hline & Visita técnica & 1 & Metodologia & 1 & Aprendizagem & $\perp$ \\
\hline & Currículo & 1 & $\begin{array}{l}\text { Inclusão e exclusão } \\
\text { social }\end{array}$ & 1 & $\begin{array}{l}\text { Conhecimento } \\
\text { e cultura }\end{array}$ & 1 \\
\hline & $\begin{array}{l}\text { Institucionalização } \\
\text { do curso }\end{array}$ & 1 & Sustentabilidade & 1 & & \\
\hline
\end{tabular}

Quadro 1 - Descritores 2 a 5 das dissertações e teses sobre ensino superior em Turismo Brasil - 2000-2009 (continua) 
Fonte: Elaboração própria, 2011.

\begin{tabular}{|c|c|c|c|c|c|c|}
\hline \multirow{2}{*}{$\begin{array}{c}\text { Tema } \\
\text { (Descritor 1) }\end{array}$} & \multicolumn{2}{|l|}{$\begin{array}{c}\text { Subtema } \\
\text { (Descritor 2) }\end{array}$} & \multicolumn{2}{|l|}{$\begin{array}{c}\text { Subtema } \\
\text { (Descritor 3) }\end{array}$} & \multicolumn{2}{|l|}{$\begin{array}{c}\text { Subtema } \\
\text { (Descritor 4) }\end{array}$} \\
\hline & Nome & No & Nome & No & Nome & No \\
\hline \multirow{3}{*}{$\begin{array}{l}\text { Pós- } \\
\text { Graduação } \\
\text { em Turismo e } \\
\text { Hospitalidade }\end{array}$} & $\begin{array}{ll}\text { Bibliometria } \\
\text { cienciometria }\end{array}$ & 1 & $\begin{array}{l}\text { Institucionalização } \\
\text { científica }\end{array}$ & 1 & $\begin{array}{l}\text { Pós-graduação } \\
\text { stricto sensu }\end{array}$ & 1 \\
\hline & Formação docente & 1 & $\begin{array}{l}\text { Pós-graduação } \\
\text { lato-sensu }\end{array}$ & 1 & & \\
\hline & $\begin{array}{l}\text { Produção } \\
\text { acadêmica }\end{array}$ & 1 & $\begin{array}{ll}\begin{array}{l}\text { Produção } \\
\text { conhecimento }\end{array} & \text { do } \\
\end{array}$ & 1 & $\begin{array}{l}\text { Pós-graduação } \\
\text { stricto-sensu }\end{array}$ & 1 \\
\hline $\begin{array}{l}\text { Graduação } \\
\text { em Turismo e } \\
\text { Lazer }\end{array}$ & Formação & 1 & Estágio & 1 & Teoria e prática & 1 \\
\hline \multirow{4}{*}{$\begin{array}{l}\text { Graduação } \\
\text { em Turismo e } \\
\text { Hotelaria }\end{array}$} & Atuação docente & 1 & Desempenho & 1 & & \\
\hline & $\begin{array}{ll}\text { Ensino } & \text { de } \\
\text { administração } & \end{array}$ & 1 & & & & \\
\hline & $\begin{array}{l}\text { Formação } \\
\text { profissional }\end{array}$ & 1 & & & & \\
\hline & Cursos superiores & 1 & & & & \\
\hline \multirow[t]{8}{*}{$\begin{array}{l}\text { Graduação } \\
\text { em Turismo }\end{array}$} & Mentoria & 1 & $\begin{array}{l}\text { Professores } \\
\text { universitários }\end{array}$ & 1 & Papel e atuação & 1 \\
\hline & $\begin{array}{ll}\text { Ensino } & \text { de } \\
\text { administração } & \end{array}$ & 2 & & & & \\
\hline & $\begin{array}{ll}\text { Produção } & \text { do } \\
\text { conhecimento }\end{array}$ & 1 & & & & \\
\hline & Educação ambiental & 1 & $\begin{array}{l}\text { Bacharel } \\
\text { turismo }\end{array}$ & & & \\
\hline & Políticas públicas & 1 & $\begin{array}{l}\text { Formação } \\
\text { profissional }\end{array}$ & 1 & & \\
\hline & Visita técnica & 1 & Metodologia & 1 & Aprendizagem & 1 \\
\hline & Currículo & 1 & $\begin{array}{l}\text { Inclusão } \\
\text { exclusão social }\end{array}$ & 1 & $\begin{array}{l}\text { Conhecimento e } \\
\text { cultura }\end{array}$ & 1 \\
\hline & $\begin{array}{l}\text { Institucionalização } \\
\text { do curso }\end{array}$ & 1 & Sustentabilidade & 1 & & \\
\hline
\end{tabular}

Quadro 1 - Descritores 2 a 5 das dissertações e teses sobre ensino superior em Turismo Brasil - 2000-2009 (continua)

Fonte: Elaboração própria, 2011.

\begin{tabular}{|c|c|c|c|c|c|c|}
\hline \multirow{2}{*}{ Descritor 2} & \multicolumn{2}{|l|}{ Descritor 3} & \multicolumn{2}{|l|}{ Descritor 4} & \multicolumn{2}{|c|}{ Descritor 5} \\
\hline & Nome & No & Nome & No & Nome & No \\
\hline \multirow{8}{*}{$\begin{array}{l}\text { Graduação } \\
\text { em Turismo }\end{array}$} & Gestão institucional & 3 & Hospitalidade & 1 & & \\
\hline & Interdisciplinaridade & 3 & $\begin{array}{l}\text { Cultura } \\
\text { organizacional }\end{array}$ & 1 & & \\
\hline & Hospitalidade & 1 & & & & \\
\hline & $\begin{array}{l}\text { Formação } \\
\text { profissional }\end{array}$ & 6 & $\begin{array}{l}\text { Mercado } \\
\text { profissional }\end{array}$ & 2 & & \\
\hline & Educação turística & 1 & Empreendedorismo & 1 & & \\
\hline & $\begin{array}{l}\text { Competência em } \\
\text { informação }\end{array}$ & 1 & Discente & 1 & & \\
\hline & Ensino de geografia & 2 & & & & \\
\hline & Evolução dos cursos & 1 & Visão estrutural & 1 & & \\
\hline
\end{tabular}




\begin{tabular}{|c|c|c|c|c|c|}
\hline $\begin{array}{l}\text { Comportamentos } \\
\text { profissionais }\end{array}$ & 1 & Aprendizagem & 1 & & \\
\hline Papel do docente & 1 & $\begin{array}{l}\text { Formação } \\
\text { bacharel }\end{array}$ & 2 & $\begin{array}{l}\text { Avaliação } \\
\text { Institucional }\end{array}$ & 1 \\
\hline $\begin{array}{ll}\text { Projeto } & \text { político } \\
\text { pedagógico } & \\
\end{array}$ & 1 & & & & \\
\hline Ingressantes & 1 & $\begin{array}{l}\text { Vivências } \\
\text { acadêmicas }\end{array}$ & 1 & & \\
\hline Sustentabilidade & 1 & Interdisciplinaridade & 1 & & \\
\hline Docente & 1 & $\begin{array}{l}\text { Perfil acadêmico- } \\
\text { profissional }\end{array}$ & & & \\
\hline $\begin{array}{l}\text { Educação superior } \\
\text { em turismo }\end{array}$ & 1 & $\begin{array}{ll}\text { Projeto } & \text { político } \\
\text { pedagógico } & \\
\end{array}$ & 1 & & \\
\hline $\begin{array}{l}\text { Implantação do } \\
\text { curso }\end{array}$ & 1 & & & & \\
\hline Disciplina & 1 & Geografia física & 1 & & \\
\hline Disciplina & 1 & Transportes & 1 & & \\
\hline
\end{tabular}

Quadro 1 - Descritores 2 a 5 das dissertações e teses sobre ensino superior em Turismo Brasil - 2000-2009 (continuação)

Fonte: Elaboração própria, 2011.

Passando para as pesquisas sobre a Graduação em Turismo, as quais são mais abundantes, tem-se um grupo que trata da implantação e evolução dos bacharelados em turismo no Brasil, ao lado das políticas públicas na formação desse profissional, cobrindo um período significativo que vai da década de 1960 ao início da década de 2000. Na fase de surgimento dos cursos superiores de Turismo, Teixeira (2007) aborda o contexto da década de 1960 com a criação da $\operatorname{Embratur}^{6}$ (1966) e a valorização do lazer e do ócio; e Celeste Filho (2002) ressalta a criação dos cursos em faculdades privadas, o que remete às discussões acerca da privatização do ensino superior em geral e das respectivas políticas adotadas (SOUZA, 2001; DENCKER, 2006; REJOWSKI, 2010).

Em relação à proposta de formação desse bacharel, os pesquisadores analisaram temáticas relacionadas à: elaboração de projetos pedagógicos de cursos e a adequação de diferentes projetos às diretrizes curriculares; visita técnica enquanto prática pedagógica e suas contribuições; estreita relação entre o trabalho de conclusão de cursos e os docentes orientadores na produção de conhecimento. Especificamente quanto ao trabalho de conclusão

${ }^{6} \mathrm{Na}$ época Empresa Brasileira de Turismo, hoje conserva a sigla como Instituto Brasileiro de Turismo. 
de curso, Meirelles (2002) apresenta um interessante diagnóstico no curso estudado, e sobre a elaboração de projetos pedagógicos de cursos, Schindwein (2003) alerta para o distanciamento da realidade e sua conseqüente padronização:

[...] a matrícula na disciplina TCC deve acontecer em dois momentos da graduação; há excesso de alunos por cada docente orientador; inexiste local adequado para a orientação; há necessidade de se sensibilizar o aluno, logo no início do curso, para a importância do ato de ler, refletir e escrever (MEIRELLES, 2002, s.p.).

A pesquisa apresenta um diagnóstico que reflete o distanciamento com questões de ordem social, cultural e econômico que interferem na elaboração dos projetos pedagógicos e conseqüentemente a padronização dos mesmos (SCHLINDWEIN, 2003, s.p.).

Sobre os conteúdos disciplinares, as pesquisas enfatizam a Geografia na formação do bacharel em Turismo e Hotelaria, além das que tratam de conteúdos de Administração, Educação Ambiental (Educação), Empreendedorismo e Transportes. Essa ênfase na Geografia indica que essa é uma das áreas disciplinares básicas na formação superior em Turismo, e reflete a "antiguidade" dos estudos geográficos assinalada por Rejowski (1997; 2010).

Os pesquisadores mostram a importância, carência ou adequação de conteúdos dessas disciplinas, a presença de conteúdos em outras disciplinas ou atividades práticas, e as deficiências ou incoerências de metodologias adotadas. Dentre esses, cita-se Câmara (2004, s. p.) que ao tratar da Educação ambiental indica a falta de ações efetivas para trabalhar o conteúdo:

[...] as ações acontecem sem qualquer proposta de integração disciplinar [...]. O desenvolvimento de uma educação ambiental [...] exige um investimento institucional e dos docentes. Seria necessária a introdução da educação ambiental nos documentos oficiais dos cursos, criando-se uma obrigatoriedade de sua prática, e ainda: uma reformulação curricular que permita uma efetiva incorporação da educação ambiental, a capacitação de docentes para a ação interdisciplinar, o incentivo à participação na pesquisa e na extensão, a adoção e implementação de estratégias pedagógicas interdisciplinares e uma avaliação permanente e coletiva de todo o processo formativo. 
Excluindo o Empreendedorismo, uma preocupação mais recente na formação superior, nota-se que as outras disciplinas enfocadas estão presentes no modelo de estudos turísticos de Jafari e Ritchie (1981). Esse fato poderia a princípio indicar que tal modelo teria fundamentado as propostas de formação do bacharel em Turismo no Brasil, muito mais do que o modelo de Tribe (1997). No entanto, sabe-se que os bacharelados em Turismo no Brasil se basearam no modelo da escola politécnica de Madri (BARRETTO; TAMANINI: SILVA (2004), e é provável que posteriormente tenham sido influenciados pelo SISTUR proposto por Beni (2001).

Por outro lado, a abordagem teórica das pesquisas investigadas não pode ser constatada, pois não estava explícita nos resumos consultados. Assim também não se pode, ao contrário do estudo de Possamai, Marinho e Santos (2009), verificar em que plataforma de estudo de Jafari (1994) a pesquisa estaria inserida.

Relacionadas à proposta de formação há pesquisas que abordam a interdisciplinaridade, sustentabilidade, hospitalidade e inclusão e exclusão social, refletindo, portanto, a preocupação com o turismo sustentável, responsável e inclusivo. Desses temas, o mais enfocado foi a interdisciplinaridade, a partir de concepções do termo, práticas e enfoques relacionados à sustentabilidade e à hospitalidade (DENCKER, 2000; MARGONI, 2006; MAGALHÃES, 2009).

Particularmente sobre a sustentabilidade, destaca-se a proposta de um modelo de educação superior de Silva (2005, s. p.), onde a instituição de ensino teria um papel relevante na promoção de valores, competências e habilidades para um atuar sustentável. Sobre a inclusão social, aparece a proposta de construção do currículo com base no conceito de qualidade social, na identidade dos cursos e na sua função social, esta última fundamentada em valores como ética, tolerância, solidariedade, igualdade social e democratização das relações de ensino (CARNEIRO, 2008). Em relação à hospitalidade, esta deve ser inserida no projeto pedagógico do curso sendo 
aplicada não apenas como termo isolado nas matrizes curriculares, mas também como aspecto a ser discutido durante todo o processo de formação (SILVA, 2007, s.p.).

Essas três pesquisas inovadoras confirmam a busca de novos paradigmas da educação superior em Turismo, pois não acompanharam o movimento. Ao mesmo tempo, se alinham à inclusão da hospitalidade como uma força de pressão ou um valor da educação turística como citado por Sogayar e Rejowski (2011).

Outro subtema presente é a formação profissional em vários aspectos, tratando de vivências acadêmicas, competências, habilidades, comportamentos profissionais, perfil acadêmico-profissional e visão dos egressos. Nos trechos abaixo nota-se o discurso sobre a aproximação da academia ao mercado, e a realidade de um amplo mercado versus a não inserção de egressos:

[...] as competências desenvolvidas pelos cursos superiores de turismo atendem parcialmente às exigências do mercado de trabalho do setor turístico de Natal, no que se refere às competências necessárias para o profissional do setor. Torna-se imprescindível uma maior aproximação entre o mercado de trabalho e a academia, visto que o dinamismo do mundo do trabalho do setor turístico exige profissionais preparados para atender às crescentes exigências em termos de formação e experiência (FORNARI, 2006, s.p.).

Enfatiza-se que os egressos consideram que o curso os motivou a ser profissionais éticos, interferindo ativamente no papel dos mesmos enquanto cidadãos, alcançando o objetivo primordial de uma universidade. No entanto, questiona-se o amplo mercado de trabalhado sugerido mediante a não atuação dos bacharéis na área e na afirmação dos mesmos de que há pouca interferência do curso em sua atuação profissional específica (MOTA, 2007, s. p.).

Ainda sobre a Graduação em Turismo têm-se as pesquisas que abordam a avaliação institucional da formação, o posicionamento estratégico de um curso com base na economia do conhecimento, a capacitação do docente e a gestão universitária privada. Dentre essas se destaca a de Degrazia (2006, s.p.) para quem o curso estudado, mesmo aceitando as exigências da 
economia do conhecimento, pouco lança mão de recursos estratégicos para posicionar-se no mercado.

No que se refere às pesquisas que trataram de cursos de pós-graduação em Turismo e Hospitalidade, uma enfocou os cursos lato sensu enfocando especificamente o docente, e duas os cursos stricto sensu, com foco na produção do conhecimento. No primeiro caso, Gaeta (2007) trata da formação do docente a partir da análise de um curso de especialização em Docência em Turismo e Hotelaria, concluindo que

[...] esse nível de ensino pode se tornar uma opção para a formação de professores do ensino superior desde que fundamentados em proposta educacional consistente e séria, em currículo desenhado criteriosamente conforme os princípios da área de estudos que pretende abranger $\mathrm{e}$ corpo docente adequadamente preparado. (GAETA, 2007, s.p.)

No segundo caso, Fedrizzi (2008) realiza um estudo centrado em um conjunto de dissertações defendidas do Mestrado em Hospitalidade da Universidade Anhembi Morumbi, no período de 2004 a 2007. Embora tenha se baseado em Rejowski (1997) vai além sob o ponto de vista metodológico, pois analisa características dos discentes e do programa, para então tratar das abordagens territoriais e temáticas das pesquisas. É a primeira estudiosa que classifica o conhecimento gerado sobre Hospitalidade na forma de um sistema composto de dez facetas, que pode, então, ser uma primeira iniciativa para a elaboração de um vocabulário controlado da área de Hospitalidade. Esclarecese que o tema hospitalidade é amplo e transcende o Turismo, o qual figura como uma das suas facetas - Hospitalidade Turística.

Já Momm (2009) trata da institucionalização do campo de estudo do Turismo, a partir da produção científica dos programas de pós-graduação stricto sensu no Brasil, no período de 2000 a 2006. Indica algumas situações preocupantes na trajetória desses programas, cuja consolidação parece ainda não ter sido alcançada.

[...] a institucionalização social do campo aponta instabilidade na estrutura dos programas, sinalizando as oscilações no total de docentes e das linhas de pesquisa existentes no período de 2000 a 2006. Sobre a 
institucionalização cognitiva do campo de estudo, sinaliza-se que há alto grau de dispersão quanto à aderência de docentes nas linhas de pesquisa, quanto às classes temáticas e linhas de pesquisa do programa de mestrado em Turismo e Hotelaria da Univali/SC, e quanto às classes temáticas e linhas de pesquisa de todos os programas (MOMM, 2009).

Essas pesquisas sobre a pós-graduação mostraram aprofundamento das temáticas investigadas com significativa contribuição aos estudos turísticos: a formação docente, a partir da análise de um curso lato sensu; a classificação do conhecimento sobre Hospitalidade em facetas, com base em dissertações de mestrado; e a institucionalização do campo do Turismo, considerando a produção acadêmica de mestrados da área. A primeira foi desenvolvida em programa de Educação e as outras duas em programas de Ciência da Informação.

\section{Considerações finais}

Este artigo apresentou o mapeamento da produção científica sobre o ensino superior em Turismo no Brasil, a partir de um conjunto de 45 dissertações e teses cobrindo o período de uma década - a de 2000. Assim, caracterizou essas pesquisas, demonstrando a sua evolução, classificou e analisou o conteúdo dessas pesquisas, de forma a compreender a abrangência do conhecimento nelas produzido, e discutiu essa produção científica frente aos estudos da área e aos vocabulários controlados da mesma.

Constatou-se que as pesquisas sobre o ensino superior em Turismo são recentes, pois começaram a ser desenvolvidas somente na década de 2000 e refletem as políticas públicas normativas do ensino superior. O perfil dos autores ficou comprometido pela inexistência do currículo Lattes ou pela falta ou dados incompletos neste. Mesmo assim, o tema foi mais estudado por pesquisadoras, o que pode indicar ser um "tema feminino", com graduação em Turismo e área afins, atuando como docente.

De outro lado, um pequeno grupo de orientadores orientou mais de uma tese, não consolidando uma linha de pesquisa sobre o tema, mesmo nas 
instituições com mestrado na área (UCS, UNIVALI e UAM). A concentração das pesquisas nas regiões Sudeste e Sul já era esperada, face à realidade dos programas existente. O destaque para o estado de São Paulo se deve principalmente aos programas da USP, apesar da extinção do seu mestrado e linha de pesquisa em Turismo e Lazer.

As duas principais áreas produtoras, a Educação e a Comunicação/Turismo também não surpreenderam, ao contrário da Ciência da Informação que, embora com pouca representatividade, indica o interesse em investigar a institucionalização do campo do turismo e da produção de conhecimento no mesmo.

$\mathrm{Na}$ análise temática, deparou-se com a inconsistência e fragilidade de resumos e palavras-chave, já observadas por outros estudiosos, o que dificultou o seu aprofundamento. Apesar disso, ao lado do estudo sobre curso, currículo, políticas públicas, discentes, docentes, competências profissionais e componentes curriculares (disciplinas, estágio, visita técnica), os pesquisadores também se debruçaram sobre temas atuais e emergentes tais como qualidade, interdisciplinaridade, inclusão e exclusão social, hospitalidade, economia do conhecimento e sustentabilidade.

A abordagem de estudos não pode ser aprofundada, pois não havia indicação explícita nos resumos das pesquisas. Ao mesmo tempo, considera-se que tanto a sustentabilidade quanto a hospitalidade são inerentes à formação superior em Turismo, e que deveriam ter maior representatividade na produção científica estudada. Porém, um pequeno grupo de pesquisas mostrou reais preocupações em prol de um novo paradigma dos estudos turísticos, o que indica a atualidade e até a inovação dessas pesquisas.

A fim de avançar na compreensão do ensino superior em Turismo e Hospitalidade no Brasil, há necessidade de novas pesquisas, tanto sobre a produção científica investigando os documentos na íntegra, quanto sobre outros aspectos envolvidos, inclusive o declínio da oferta desses cursos, as diferentes realidades dos estados e regiões brasileiras, assim como a 
comparação com outros países, visando, por exemplo, um panorama sul, latino ou ibero-americano.

\section{Referências}

ANSARAH, M. G. R. Formação e capacitação do profissional em turismo e hotelaria. Reflexões e cadastro das instituições educacionais do Brasil. 2.ed. São Paulo: Aleph, 2002.

BARRETTO, M.; TAMANINI, E.; SILVA, M. P. da. Discutindo o ensino universitário de turismo. Campinas: Papirus, 2004.

BASTOS, S. A produção científica do mestrado em hospitalidade (2002-2008). Revista Hospitalidade. São Paulo, ano V, n. 2, p. 120-132, jul.-dez. 2008.

BASTOS, S.; FEDRIZZI V. F. A produção científica do mestrado em hospitalidade (2002-2007). Revista Hospitalidade. São Paulo, ano IV, n. 1, 90100, jan.-jun. 2007.

BENI, M. C. Sistema de turismo: construção de um modelo teórico referencial para a aplicação na pesquisa em Turismo. Tese (Doutorado em Ciências da Comunicação), São Paulo: USP, 1988.

BENI, Mário Carlos. Análise estrutural do turismo. São Paulo: Senac, 2001.

BOTERILL, D. A survey of doctoral theses accepted universities in the UK and Ireland related to tourism. Tourist Studies, v. 2, n. 3, p. 283-311, 2002.

BRUSADIN, Leandro Benedini. Estudo da avaliação do Programa Nacional de Municipalização do Turismo - PNMT na gestão do presidente Fernando Henrique Cardoso. Revista Hospitalidade, São Paulo, ano 2, n. 2, p. 87-111, 2. sem. 2005.

CÂMARA, Margarida Maria Drumonnd. Educação ambiental no curso superior de Turismo: estudo em um curso pioneiro de Belo Horizonte. Dissertação (Mestrado em Educação), Belo Horizonte, MG: PUC/MG, 2004).

CARNEIRO, Ana Luzia Magalhães de. A formação acadêmico-profissional para inclusão social nos cursos superiores de turismo: dos aspectos socioeconômicos à discussão curricular. Tese (Doutorado em Educação), São Paulo, SP: PUC/SP, 2008.

CARVALHO, Mariana Aldrigui. Os números do ensino superior em turismo e hospitalidade no Brasil - 2001 a 2006. In: SEMINÁRIO DA ANPTUR, V. Belo Horizonte, 2008. Anais. Belo Horizonte: Anptur, 2008.

CELESTE FILHO, Macioniro. A institucionalização do turismo como curso universitário (décadas de 1960 e 1970). Dissertação (Mestrado em Educação) São Paulo, SP: PUC/SP, 2002.

DALLAGNOLLO, Décio César. A formação de graduação em Turismo na Universidade Regional de Blumenau: um olhar a partir do estágio. Dissertação (Mestrado em Educação), Blumenau: FURB, 2009.

DEGRAZIA, Carolina Figueiró. Cursos superiores de turismo na economia do conhecimento: posicionamento estratégico de um curso de turismo no Rio 
Grande do Sul. Dissertação (Mestrado em Turismo), Caxias do Sul, RS: UCS 2006.

DENCKER, A. de F. M. Estado de Educação no Brasil: O caso do ensino em turismo. In: CONGRESSO BRASILEIRO DE CIÊNCIAS DA COMUNICAÇÃO, XXIX. Brasília: Intercom, 2006. Anais. Brasília: Intercom, 2006.

DENCKER, Ada de Freitas Maneti. A pesquisa e a interdisciplinaridade no ensino superior - uma experiência no curso de turismo. Tese (Doutorado em Ciências da Comunicação), São Paulo: USP, 2000.

ESPAÑA. Ministerio da Economia. Secretaria General de Turismo. Centro de Documentación Turística de España. Thesauro de turismo y ocio. Madrid: IET, 2003, p. 177-186.

FEDRIZZI, V. O conhecimento gerado no programa de mestrado em hospitalidade. Dissertação (Mestrado em Hospitalidade), São Paulo:UAM, 2008. FORNARI, Ivanna Schenkel. Educação superior em turismo: o profissional de turismo frente às competências exigidas pelo mercado de trabalho do setor hoteleiro em Natal. Dissertação (Mestrado em Administração), Natal, RN: UFRN, 20076.

GAETA, M. C. D. Diagnóstico da atuação dos professores universitários em turismo e hotelaria. Dissertação (Mestrado em Educação), São Paulo, SP: PUCSP, 2001.

- Formação docente para o ensino superior: uma inovação em cursos de lato sensu. Tese (Doutorado em Educação), São Paulo, SP: PUC-SP 2007.

GOMES, C. M. Pesquisa científica em lazer no Brasil. Bases documentais e teóricas. Dissertação (Mestrado em Ciências da Comunicação), São Paulo: USP, 2004.

HALL, M. Tourism a subject of post-graduate dissertation in Austrlia. Annals of Tourism Research, Menmonie, vol. 18, n. 3, p. 520-523 (Research Notes and Reports).

JAFAR, Jafari. La cientifización del turismo. Estudios y Perspectivas en Turismo. Buenos Aires, v. 3, n.1, p. 7-36, jan. 1994.

JAFAR, Jafari.; AASER, Dean. Tourism as the subject of doctoral dissertations. Annals of Tourism Research, v.15, p. 407-429, 1988.

JAFAR, Jafari; RICHIE, J.Brent. Towards a framework for tourism education: problems and prospects. Annals of Tourism Research, v. 8, n.1, 13-33.

JAFAR. Jafar. El turismo como disciplina científica: sociología del turismo, Política y sociedad, v. 42, n. 1, p.39-56, 2005.

KIM, Seon-Ha. Content Analysis: Annals of Tourism Research and Journal of Travel Research. (Thesis Master's). Wisconsin: University of Wisconsin-Sout, 1998.

LIMA, Juliana Ribeiro de. Ensino superior em turismo no Brasil: estudo da produção acadêmica (2000-2009). Dissertação (Mestrado em Hospitalidade), São Paulo: UAM, 2011.

MAGALHÃES, Margarida Molina. Turismo, Educação e Ambiente: uma Viagem Interdisciplinar. Dissertação (Mestrado em Ciências da Saúde e do Ambiente), Niterói, UNIPLI, 2009. 
MARGONI, Catherine Cavalcanti. Reflexões sobre a aplicação da interdisciplinaridade em cursos de turismo. Dissertação (Mestrado em Hospitalidade), São Paulo, SP: UAM, 2006).

MATIAS, Marlene. Turismo; formação e profissionalização: 30 anos de história. Barureri: Manole, 2002.

MEIRELLES, Leila Glória do Colto Gurjão de Freitas. O trabalho de conclusão de curso como possibilidade de produção do conhecimento no ensino superior: curso de turismo da Universidade Federal do Pará. Dissertação (Mestrado em Educação), Campinas, SP: PUC - Campinas, 2002.

MÖESCH, M. Epistemologia social do turismo. Tese (Doutorado em Ciências da Comunicação), São Paulo: USP. 2004, v. 1-2.

MOMM, C. F.; SANTOS, R. M. dos O estado da arte da área de pesquisa do turismo no Brasil: período de 2000 a 2006. Turismo \& Desenvolvimento. Aveiro, v. 1, n. 13-14, p. 373-385, 2010.

MOMM, Cristiane Fabíola. O conhecimento científico em turismo no Brasil: curso de pós-graduação (stricto sensu) - período de 2000 a 2006. Dissertação (Mestrado em Ciência da Informação), Florianópolis, SC: UFSC, 2009.

MOTA, Karol Monteiro. Formação superior em turismo da Unifor (CE): Proposta, realidade e reflexões. Dissertação (Mestrado em Turismo), Caxias do Sul, RS: UCS, 2007.

NEVES JUNIOR, Frederico Guilherme Serrano. Competências em Turismo e Hotelaria: análise comparativa entre normativas do MEC, cursos superiores e mercado hoteleiro de Belo Horizonte. Dissertação (Mestrado em Administração), Belo Horizonte, MG: FEAD, 2007.

OMT - ORGANIZACIÓN MUNDIAL DEL TURISMO. Secretaría de Estado de Turismo de Francia. Tesauro de turismo y ocio. OMT, 2001, v. 5, p. 646-675.

PANOSSO NETTO, A. Filosofia do turismo. Teoria e epistemologia. São Paulo: Aleph, 2005.

PINTO, D.; BABINSKI, L. R. Produção acadêmica do mestrado em turismo da Universidade de Caxias do Sul: estudo comparativo das dissertações (2002 a 2004 - 2004 2005). In: CONFERÊNCIA DA ANFLRTH PARA AMÉRICA LATINA, III, 2006. Anais. São Paulo: Senac, 2006.

REJOWSKI, M. Pesquisa científica em turismo no Brasil: comunicação, produtividade e posicionamento (1990 a 2005). São Paulo: UAM, 2010. (Relatório de pesquisa - CNPq).

- Realidade turística nas pesquisas científicas: visão de pesquisadores e profissionais. Tese (Livre-Docência em Teoria do Turismo e do Lazer), São Paulo: USP, 1997, v. 1.

. Pesquisa acadêmica em turismo no Brasil (1975 a 1992): configuração e sistematização documental. Tese (Doutorado em Ciências da Comunicação), São Paulo: USP, 1993.

RUSCHMANN, Doris. Turismo no Brasil: análises e tendências. São Paulo: Manole, 2002.

SANTOS, M. M. dos; PASSAMAI, A. M. de P.; MARINHO, M. F. Pesquisa em turismo: panorama das teses de doutorado produzidas no Brasil de 2005 a 
2007. Revista Brasileira de Pesquisa em Turismo, São Paulo, v. 3, n. 3, p. 333.

SCHLINDWEIN, Cristine Maria. O projeto pedagógico no ensino superior em turismo. Dissertação (Mestrado em Turismo e Hotelaria), Balneário Camboriú, SC: UNIVALI, 2003.

SCHLÜTER, Regina. Investigación en turismo y hotelería. Buenos Aires: CIET, 2000.

SILVA, Francisca de Paula Santos da. Educação superior sustentável: uma análise de cursos de turismo. Tese (Doutorado em Educação), Salvador, BA: UFB, 2005.

SILVA, Juliana do Prado. Cursos de turismo sob a ótica da hospitalidade: Estudo de caso do curso de turismo Uniaraxá-MG. (Mestrado em Hospitalidade), São Paulo, SP: UAM, 2007.

SOGAYAR. R. L.; REJOWSKI, M. Ensino superior em turismo em busca de novos paradigmas educacionais: problemas, desafios e forças de pressão. Turismo - Visão \& Ação, Balneário Camburiú, v.13, n. 3, p. 282, 298.

SOUZA, Paulo Nathanael Pereira de. $L D B$ e educação superior: estrutura e funcionamento. São Paulo: Piomeira Thomson, 2001.

TEIXEIRA, Sergio Henrique Azevedo. Cursos superiores de Turismo. Condicionantes sociais de sua implantação: uma abordagem histórica (1968/1976). Dissertação (Mestrado em Educação) Itatiba: USF, 2007.

TRIBE, J. The indiscipline of tourism. Annals of Tourism Research. Pergamon, v. 24, n. 4, p. 638-657, 1997.

Artigo recebido em setembro de 2011.

Aprovado para publicação em dezembro de 2011. 